\title{
GENERAL E-BUSINESS METHODS IN AGILE CONTEXT
}

\author{
Paul George OPRESCU \\ Bucharest University of Economic Studies, Romania \\ Doctoral School of Economic Informatics \\ oprescugp@gmail.com
}

\begin{abstract}
Easy to use, but difficult to understand and master, technology leaves its mark in almost every field of our contemporary society. Commerce is one of the most widespread concepts in history, being the bedrock of human evolution through its various forms and practices. Combining the two will help humanity reach new heights in terms of online trading and understanding customer needs. The need for face to face interaction between the buyer and the supplier has been completely removed with the emergence of e-commerce and the development of e-commerce platforms. Influenced by both external and internal factors, to gain success, an online platform captures the attention of buyers, analyzing their behavior through data processing algorithms in order to obtain business information needed for the company's business strategy. With Big Data and Data Mining, the profile of any consumer is projected directly into the platform, thus communicating the necessary information to predict the behavior in future platform visits.
\end{abstract}

Keywords: e-commerce platforms, e-business: Business to Business (B2B) \& Business to Consumer (B2C), Supply-Chain Management, drop shipping, IoT and data mining, Elasticsearch

JEL classification: M15, M21, M3

DOI: $10.12948 / \mathrm{ie} 2019.04 .03$

\section{Introduction}

Due to recent technological changes, there may be difficulties in analyzing an e-commerce platform and determining the key factors that lead to a successful business that differentiates from the ones already on the market.

[1] An electronic business is the exchange of services and products via the Internet between several types of consumers and businesses in order to make profit. In most cases there is ambiguity when involving this type of business activity, the concept being reduced to online shopping, consumers not understanding the mechanics that reside behind. Among the usual consumers, other companies and entrepreneurs with a vision of the market also participate in this type of commerce. Starting from the layout of the page and the technical characteristics, reaching the executive board that decides the future of the business, all elements are interconnected and communicate with each other through business information. Managerial skills and creativity are important in an e-business, but in order to maintain its integrity and stability, the investment must be on the same level as the results, combining resources to deliver a product that meets the market requirements being a bold and difficult process and can have many financial consequences. The rapid evolution of technology provides a competition to those who want to participate in this market. Everything revolves around the online concept, which is predominant in any field and is the key to a long-lasting business expansion. There is no person who does not have access to an Internet connected device nowadays and this predisposition to Internet-Of-Things is the future of humanity towards an interconnected society. Activities that were going on every day with some difficulty have now been replaced 
or assisted by technology. Due to this technological advancement, e-business is in the best development and integration period. At marketing level, there is no need for a direct face to face relationship between the buyer and the supplier, all the products being highlighted directly through the e-commerce platform. Over time, people's interaction with e-commerce platforms has made it possible for computer science engineers to refine the analysis and data mining algorithms responsible for a better understanding of the consumer's needs and transforming them into services and design. At the heart of an electronic business, the efficient use of both hardware and software resources in line with customer requirements is essential in maintaining flexibility and a place on the market.

\section{Factors that influence the success of e-commerce platforms}

The most common forms of e-commerce are B2B or business-to-business and B2C or businessto-consumer. In business-to-consumer, customers acquire through e-commerce platforms products of different types and forms according to their needs. There are many factors that influence the customer's interest and determine the platform's quality factor. Used by the most successful companies, inspiring professionalism, the simplicity of the design is one of the most important aspects of the technological era. The consumer has a well-defined goal when accessing the web page, to purchase the product as quickly as possible without being distracted by the other elements of the page, regardless of their complexity. Behind any seemingly simple application for the average consumer, there are concepts, ideas, algorithms and technologies that together make up the complexity of the platform. The interface through which the user accesses the site must be user-friendly and intuitive and the engine behind the design should ensure its functionality. Among the main user-friendly features a web site contains: the search bar and the algorithm behind it that helps the buyer to find results as close as possible to the product they desire; search filters by price, categories, subcategories and other technical or descriptive specifications; product-level details and placement on the page; simple page colors to ensure easy access; payment methods through which the consumer can complete the order: card, bank transfer, cash on delivery, payment order; a feedback page for notes and reviews. The quality of the services offered when talking about e-commerce is not only determined by the technical support of the platform, but also by the later assistance by the company in case of delivery errors, defective products, even technical failures of the platform. The best way a company tests the competence of their software is through consumers who use it and offer positive or negative feedback. The question that the executive power of the e-business firm should discuss is what determines a consumer to buy a product online. The environment in which a person spends most of their time is the comfort zone and is therefore worthy of exploitation by any businessman. Accessibility and convenience are very important factors in every person's life and motivate them in achieving their daily activities easily, without going through a filter of thought. The availability of the platform at any time of the day highlights the superiority of the online concept over an ordinary shop. Furthermore, the individual is more likely to access the platform from anywhere regardless of whether they are currently seeking to purchase a product or just to verify certain products for subsequent purchases. A vice of people everywhere in the contemporary world is access because of habit. It plays an important role in the development of online platforms and it is what every entrepreneur wants: the personal life of a large number of people to become interconnected with his business. A business always revolves around one very important element, namely the price of the services or products offered. The online environment has an advantage over traditional stores that do not consume financial resources on employees and use automated sales and purchasing systems. Thus, operational costs are directed towards consumers by making promotions and reducing prices. Consumers are in most cases also influenced by the pricing and with the 
emergence of Internet comparison tools, transparency is inevitable. Through online stores, the range of products and services is unlimited, providing the buyer the power of choice. Here comes the availability of each company and how it manages its stocks. There is also the possibility of a monopoly on e-commerce platforms, which can be exploited at different levels, both at regional level and according to the types of products offered. Big companies such as Amazon and AliExpress are among the largest companies fighting for supremacy while developing new innovative projects. Their position on the market is the biggest advantage that these companies can have and most small platforms integrate their products and services through these successful platforms, hoping they will one day launch on their own terms. It is never known when the seats already occupied in the top will again be free to allow new enthusiasts and entrepreneurs to prepare and enter the e-commerce market. When buying a product customers need to have access to as many different payment methods as possible to encourage them in starting online transactions. An e-business has the ability to increase exponentially due to scalability on the Internet: promoting unique services and products through online marketing and electronic platforms. The number of sales on e-commerce platforms increased exponentially over time and is estimated to reach 4.9 trillion dollars by 2021 (Figure 1).

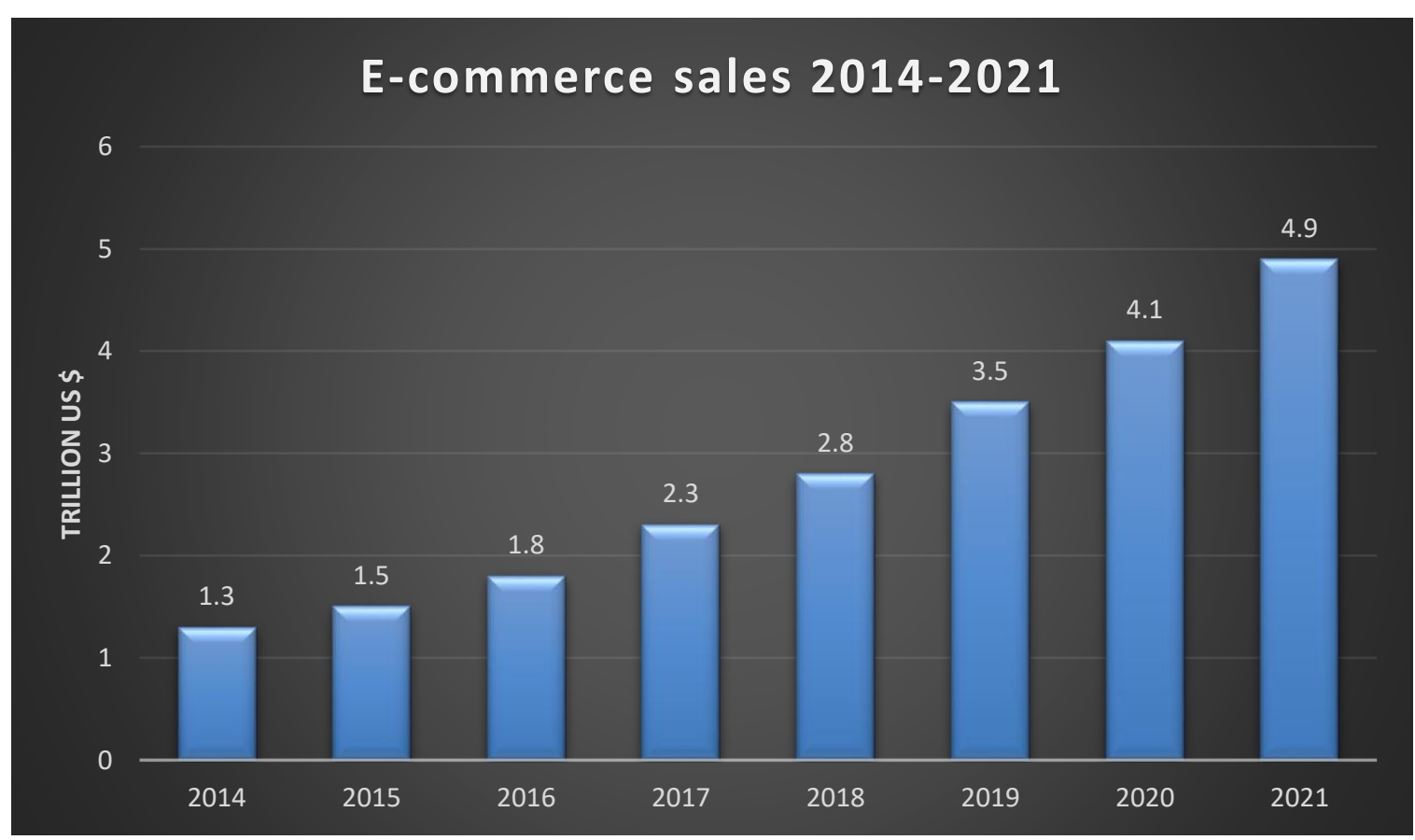

Figure 1. Number of sales on e-commerce [2]

Online marketing is much more advanced than its precursor targeting and accurately analyzing the consumer's specific needs over time and personalizing his searches, as well as displaying similar results in the form of advertisements on social media platforms.

\section{Supply-Chain Management and Drop shipping}

Like any form of commerce, either traditional or electronic, service management, information and products, their flow, production, storage, and inventory process are included in the Supply-Chain Management concept

[3]. The Supply-Chain itself is like an invisible chain of buyers, retailers, wholesalers, distributors, suppliers and manufacturers. Lack of communication and organization between participants leads to the creation of a Bullwhip effect, which represents the fluctuations between 
demand and supply within the Supply-Chain.[4] In the drop shipping model[5], the owner of the store does not have in his possession any of the displayed products, storage being handled by the supplier. The investment costs are almost negligible, all that is required being a computer and a connection to the Internet for the business to grow. The owner does not pay for bookkeeping, storage, maintenance, packing, delivery and return costs, and there is no need to continually buy products to keep the stock available. Moreover, a disadvantage would be not having control over the stock, that being held by the supplier. The profits coming from this kind of business would be minimal, since the owner actually buys the product from the supplier and re-sells it to the customers with a slightly higher price. A supplier only pays for the raw material and production cost of the product, which is much lower than the price at which the retailer buys it. One major setback would also be having to get products from different suppliers for one single customer. The more suppliers one has, the more problems could arise during the selling process. Another technique would be the outsourcing of sales and purchasing services. The retailer does not want to be responsible for the product acquisition and delivery process and thus uses the services of another company to handle the process. In the drop shipping model it's all about how you handle your customers through marketing and a good company image, while having a good relationship with the suppliers and third party companies that help with the selling process.

\section{Influence of technology on e-business}

Technology leaves its footprint in online environments through the multitude of data it gets from consumer interaction with e-commerce platforms. Their preferences can be recorded from color, type, region, size to price, payment method, quantity, managing the stock and the availability of the products, fluidizing the sale-purchase process. Consumer experience is improved by trying to understand the company's target. The ability of the executive power of the company that owns the e-commerce platform is assisted by these data collection and analysis technologies, processed with the help of the Business Intelligence and IT departments. Removing the threshold between the two and combining activities to improve decision-making is one of the most bold challenges of the technological age. The business intelligence department does not directly help increase the profits of the company, only the decision power being drastically influenced and can be the factor by which it differentiates and detaches from the competition.

In this area, the concept of EDI or Electronic Data Interchange transactions is widespread. EDI translates to the ability of a company to send services and products electronically to another company or to exchange business information inside its own company. We live in a world dominated by technological devices more and more, and that's not a novelty. The mobile phone is the most used tool in everyone's personal life, more and more people making the transition from the personal computer. The quality of mobile services increases exponentially, thus providing the most favorable environment for the development of e-business and the strategies needed to maintain the public interest. With the appearance of $5 G$ mobile communication there has been an explosion of comfort and speed when accessing information through a mobile device. Many companies have been affected with the advent of GDPR or the General Data Protection Regulation, which is a security legislation developed by the European Parliament to protect the personal data of EU citizens. Facebook, a giant in social networking, has suffered and is still under investigation on personal data security violation that should not be available to anyone and is the absolute symbol of intimacy of every person. All in all there is a sensitivity when it comes to data that is collected through e-commerce platforms, and companies have to treat the information received carefully in order to protect the integrity and security of their customers. The customization of a client's experience, however, differs from one platform to 
another through the depth of processing of personal data. However, in some cases the customer can decide what information to provide or by communicating directly with a chat-bot that simulates the behavior of an online employee.

\section{Types of e-commerce platforms in agile context}

An agile method encompasses all iterative processes through which you can develop and test a software product in a fast and efficient manner to meet all customer requirements. [6] In this principle, the testing and development of the e-commerce platform takes place at the same time, unlike the traditional methods where testing often takes place at the end of the development cycle. The client is also able to intervene throughout the cycle to provide feedback or to make new requirements about his software product. Errors are also treated at the time of testing, programmers and testers working together to quickly and efficiently complete a small step in this long process. A disadvantage would be that each development process, called a sprint, is estimated to finish after a few weeks. If the errors are not resolved, tasks will be reassigned and the next sprint will be much more loaded. It is essential to repair the errors before proceeding with the next step in the project. At the end of each sprint there is a UAT or User Acceptance Testing where the client is testing the product to ensure that the software behaves according to the specifications.

The question that any individual should ask before entering the e-business market is what kind of activity does he want to maintain and what kind of e-commerce platform suits his needs best: paid or free of charge.[7[] Generally, in order to initiate an e-commerce platform, you need to follow a few steps in this process, which the paid platforms provide without effort from the buyer. E-commerce platforms offer help and support for any problem or error encountered by the user during the subscription. The installation does not require any effort or technical programming skills from the user, therefore in the future there is no need for personal technical involvement or a developer to guarantee continuity and maintenance of the web site. Security is not user-dependent and it is solely the responsibility of those who provide these hosting services. The page design does not start from scratch, and the user can choose from a multitude of themes and colors according to their preferences. For those who want to test their technical and entrepreneurial capabilities, there are free e-commerce platforms, where users have control over the resources and constraints of the site they create. There is no external support for the user, nor is there a need for a monthly payment. For site maintenance, however, extensive programming techniques are needed, the level of difficulty being controlled by how complex a user wants to personalize their website and attract customers through its uniqueness. The best open-source e-commerce platform that is available to everyone to make improvements and share them with the rest of the developers is Magento.

Magento is an open-source e-commerce platform that encapsulates through its architecture all the tools and services needed to develop an agile electronic business. This creates a unique shopping experience by promoting dynamic products according to the consumer profile and assists him with a search engine encapsulating Elasticsearch.[8] Elasticsearch is responsible for correcting and interpreting words and guiding the user in finding the desired product. Installing such a search engine is quite affordable with predefined settings and does not require extensive programming knowledge. Behind such a technology, however, resides a high complexity for advanced and fast searches, ready to be embedded in any application. The Elasticsearch search engine is much simpler than relational databases that contain tables, rows, columns, fields, and logical schemas [9]. Traditional databases are not designed for complex text searches and certainly do not have a high performance rate when it comes to structures or information coming from other applications. Queries that would take a few seconds using SQL 
www.conferenceie.ase.ro

would run through Elasticsearch in just a few milliseconds, thus increasing the execution time exponentially.

\section{Conclusions}

Trade was among the main activities of mankind, which brought progress and prosperity together with its opportunities. With the invention of the Internet and the possibility of developing an online business, the benefits of those who participate in online transactions have grown exponentially. Both consumers and entrepreneurs interact more easily through ecommerce platforms that have replaced traditional trade methods. Either developed behind a home computer or combined with traditional means of production, the e-business can successfully capture the target market if the idea is in line with the goals. New data analysis technologies and algorithms allow any company to predict consumer behavior, to understand the needs and assist the executive power in choosing the right strategies. The design of web pages must be in a position to inspire attractiveness and trust in the services provided by the ebusiness. The smallest detail counts when you participate in a developing market where everyone wants to get a place in the train of innovation and future. Although we are aware of the presence of technology and its evolution, the human mind does not realize how fast technology grows and engulfs ours society over time.

\section{References}

[1] J. Morrish, "What is E-Commerce? An introduction to the Industry", 4 Nov 2015, [Online]. Available at: https://feinternational.com/blog/what-is-e-commerce-an-introduction-tothe-industry/

[2] A. Orendorff, "Global Ecommerce Statistics and Trends to Launch Your Business beyond Borders," $14 \quad$ Feb 2019, [Online]. Available at: https://www.shopify.com/enterprise/global-ecommerce-statistics

[3] Wikipedia, "Supply-chain management," [Online]. Accessed 12 Ian 2019, Available at: https://en.wikipedia.org/wiki/Supply-chain_management

[4] SCRC SME, "What is Supply Chain Management (SCM)?" 2 Apr 2017, [Online]. Available at: https://scm.ncsu.edu/scm-articles/article/what-is-supply-chain-management$\mathrm{scm}$

[5] M. Hayes, A. Youderian, "The Ultimate Guide to Drop shipping," [Online]. Accessed 15 Jan 2019, Available at: https://www.shopify.com/guides/dropshipping/understandingdropshipping

[6] Guru99, "Agile Model \& Methodology: Guide for Developers and Testers," 2019, [Online]. Available at: https://www.guru99.com/agile-scrum-extreme-testing.html

[7] AAAMAZING websites; 2011-2017, "Free vs. Paid e-Commerce Solutions - Which One is Right for You?" [Online]. Available at: https://www.aaamazing.com.au/86-free-vspaid-e-commerce-solutions-which-one-is-right-for-you.html

[8] Elasticsearch B.V., "The Heart of the Elastic Stack," 2019, [Online]. Available at: https://www.elastic.co/products/elasticsearch

[9] J. Vanderzyden, "What is Elasticsearch, and How Can I Use It?" 1 Sep 2015, [Online]. Available at: https://qbox.io/blog/what-is-elasticsearch 